\title{
Quantitative Analysis of Irbesartan in Commercial Dosage Forms by Kinetic Spectrophotometry
}

\author{
Nafisur Rahman, ${ }^{*}$ Masoom Raza SiddiQui, and Syed Najmul Hejaz Azmi \\ Department of Chemistry, Aligarh Muslim University; Aligarh-202002, Uttar Pradesh, India.
}

Received November 1, 2005; accepted January 26, 2006

The objective of this work is to develop a new kinetic spectrophotometric method for the determination of irbesartan in pharmaceutical formulations. The method is based on the reaction of carboxylic acid group of the oxidized irbesartan with a mixture of potassium iodate $\left(\mathrm{KIO}_{3}\right)$ and iodide $(\mathrm{KI})$ to form yellow colored triiodide ions in aqueous medium at $30 \pm 1{ }^{\circ} \mathrm{C}$. The reaction is followed spectrophotometrically by measuring the rate of change of absorbance at $352 \mathrm{~nm}$. The initial-rate and fixed-time $(\Delta A)$ methods are adopted for constructing the calibration curves, which were found to be linear over the concentration ranges of $10.0-60.0$ and $7.5-60.0 \mu \mathrm{g} \mathrm{ml}^{-1}$ respectively. The regression analysis of calibration data yielded the linear equations: rate $=-2.138 \times 10^{-6}+1.058 \times 10^{-4} C$ and $\Delta \mathrm{A}=-3.75 \times 10^{-3}+3.25 \times 10^{-3} C$ for initial rate and fixed time $(\Delta \mathrm{A})$ methods, respectively. The limit of detection for initial rate and fixed time methods are 0.21 and $2.40 \mu \mathrm{g} \mathrm{ml}^{-1}$, respectively. The various activation parameters such as $E_{\mathrm{a}}, \Delta H^{\ddagger}, \Delta S^{\ddagger}$ and $\Delta G^{\ddagger}$ are also calculated for the reaction and found to be $70.95 \pm 0.43 \mathrm{~kJ} \mathrm{~mol}^{-1}, 68.48 \pm 0.21 \mathrm{~kJ} \mathrm{~mol}^{-1}, 16.54 \pm 0.24 \mathrm{~J} \mathrm{~K}^{-1} \mathrm{~mol}^{-1}$ and $-4.94 \pm 0.07 \mathrm{~kJ} \mathrm{~mol}^{-1}$, respectively. The proposed methods are optimized and validated as per the guidelines of International Conference on Harmonisation (U.S.A.). The point and interval hypothesis tests have been performed which indicate that there is no significant difference between the proposed methods and the reference method. The methods have been successfully applied to the determination of irbesartan in commercial dosage forms.

Key words irbesartan; kinetic; spectrophotometry; validation; commercial dosage form

Irbesartan is chemically known as 2-butyl-3-[[2'-(1Htetrazole-5-yl)(1,1' -biphenyl)-4-yl]methyl]-1,3-diazaspiro[4,4]non-1-en-4-one, which is a potent, long-acting non peptide angiotensin II receptor antagonist with high selectivity for the $\mathrm{AT}_{1}$ sub type. This is potentially safe and more tolerable than other classes of antihypertensive drugs to improve symptoms, quality of life, exercise capacity, reduce hospital admissions for cardiac failure and reduce the incidence of myocardial infarction, sudden death, and death from progressive systolic failure. ${ }^{1)}$ The drug is very helpful in reducing the morbidity and mortality associated with these hypertension conditions. Therefore, it is necessary to quantitate the drug in pharmaceutical formulations.

The drug is officially listed in Martindale The Extra Pharmacopoeia. ${ }^{2)}$ The assay procedure in pure and dosage forms is not official in any pharmacopoeia and therefore the development of an analytical procedure for the determination of irbesartan in pharmaceutical preparations is of great significance. The various analytical methods such as high performance thin layer chromatography (HPTLC), ${ }^{3}$ liquid chromatography (LC), ${ }^{4}$ high performance liquid chromatography (HPLC), ${ }^{5,6)}$ capillary zone electrophoresis (CZE), ${ }^{7,8)}$ and derivative spectrophotometry ${ }^{9,10)}$ have been described for its determination.

The literature is still lacking analytical procedures based on kinetics for the determination of irbesartan in commercial dosage forms. There are certain advantages associated with kinetic methods such as ${ }^{11)}$ :

- simplicity owing to elimination of some experimental steps such as filtration, extraction prior to absorbance measurements.

- high selectivity due to the measurement of the evolution of the absorbance as a function of reaction time instead of measuring the concrete absorbance value.

- no interference from other active compounds present in the commercial dosage forms, if they resist the chemical reaction conditions.

Our present communication describes a kinetic spectrophotometric method for the determination of irbesartan in commercial dosage forms. The method is based on the oxidation of irbesartan with potassium iodate to form a carboxylic acid derivative, thus in the presence of $-\mathrm{COOH}$ group iodide is oxidized by iodate resulting in the formation of triiodide ion, which absorbs maximally at $352 \mathrm{~nm}$. The absorbance increases with time and therefore, the initial-rate and fixed-time methods are adopted for the determination of irbesartan in commercial dosage forms.

\section{Experimental}

Apparatus A Shimadzu UV-visible 1601 spectrophotometer (Model no. 1601, Kyoto, Japan) with matched quartz cells was used for spectral run. Absorbance measurement was made on Spectronic $20 \mathrm{D}^{+}$spectrophotometer (Milton Roy, U.S.A.). A water bath shaker (NSW 133, New Delhi, India) was used to maintain a constant temperature for color development.

Reagents and Standards All chemicals and reagents used were of analytical or pharmaceutical grade. Irbesartan reference standard (Batch No. IB-110021102) was kindly provided by Biochem Pharmaceutical Industries (Mumbai, India). Standard solution of irbesartan $\left(0.5 \mathrm{mg} \mathrm{ml}^{-1}\right)$ was prepared by dissolving $50 \mathrm{mg}$ in $100 \mathrm{ml}$ dimethyl sulfoxide. This solution was used to prepare calibration curve and quality control samples. Quality control samples were prepared at three concentration levels of 10,30 and $60 \mu \mathrm{g} \mathrm{ml}^{-1}$. Commercial dosage forms of irbesartan such as Irovel-150 (Sun Pharma, Mumbai, India), Irbest-150 (Biochem Pharma Industries, Mumbai, India) and Xarb-150 (Nicholas Piramal India Ltd., Mumbai, India) were obtained from local market.

A 0.05 M KI (Fluka Chemie AG, Switzerland) solution was freshly prepared in distilled water. The solution was standardized by the recommended procedure. ${ }^{12)}$ A $0.003 \mathrm{~m} \mathrm{KIO}_{3}$ (Fluka Chemie AG, Switzerland) was also freshly prepared in distilled water.

Recommended Procedures for the Determination of Irbesartan. Initial Rate Method Aliquots of $0.2-1.2 \mathrm{ml}$ reference standard solution of irbesartan $\left(0.5 \mathrm{mg} \mathrm{m}^{-1}\right)$ were pipetted into a series of $10 \mathrm{ml}$ standard volumetric flasks. To each flask, $1.8 \mathrm{ml}$ of $0.003 \mathrm{M} \mathrm{KIO}_{3}$ was added followed by $2.3 \mathrm{ml}$ of $0.05 \mathrm{M} \mathrm{KI}$ and then diluted to volume with distilled water at $30 \pm 1{ }^{\circ} \mathrm{C}$. The contents of each flask were mixed well and the increase in ab- 
sorbance at $352 \mathrm{~nm}$ was recorded as a function of time against the reagent blank prepared similarly. The initial rate of the reaction $(v)$ at different concentration was obtained by measuring the slope of the tangent to the absorbance-time plot. The calibration graph was obtained by plotting the initial rate of reaction $(v)$ versus the molar concentration of the irbesartan. The amount of the drug was calculated either from the calibration graph or the regression equation.

Fixed-Time $(\Delta \mathbf{A})$ Method In this method, the absorbance of each sample solution was measured at $352 \mathrm{~nm}$ against a reagent blank prepared similarly except drug at a preselected fixed time. The difference between the absorbance obtained at $2 \mathrm{~min}$ and the absorbance at $4,6,8$ or $10 \mathrm{~min}$ was plotted against the concentration of irbesartan to yield the calibration curve. The amount of the drug was computed either from calibration curve or from corresponding regression equation.

Determination of Irbesartan in Commercial Dosage Forms The powdered contents of 2 tablets of $150 \mathrm{mg}$ strength were weighed and grounded. The powder equivalent to $50 \mathrm{mg}$ irbesartan was stirred well with dimethyl sulfoxide. The solution was filtered through Whatmann No. 42 filter paper (Whatmann International Limited, Kent, U.K.) in a $100 \mathrm{ml}$ standard volumetric flask and the residue was washed well with dimethyl sulfoxide for complete recovery of the drug. The content of standard volumetric flask was then diluted to $100 \mathrm{ml}$ with dimethyl sulfoxide. The amount of irbesrtan was determined following the proposed procedures.

Procedure for Reference Method Aliquots of $0.05-0.6 \mathrm{ml}$ of $0.025 \%$ irbesartan were pipetted into a series of $10 \mathrm{ml}$ standard volumetric flasks and diluting to volume with ethanol. The absorbance was measured against the solvent blank at $207 \mathrm{~nm}$. The amount of the drug in a given sample was computed from the calibration graph or linear regression equation.

Validation The proposed method has been validated for specificity, linearity, precision, accuracy, recovery, limit of detection, and quantitation.

Specificity Samples of irbesartan tablets were subjected to stress conditions of light, heat and base. All stressed samples were analyzed for active irbesartan content and compared to an unstressed time zero reference solution. The time zero solution provided a reference assay value for the unstressed product. The content of degradation in the stressed and control samples was calculated relative to this assay value.

Linearity The linearity of the initial rate and fixed time methods were assessed in the concentration range $10-60$ and $7.5-60 \mu \mathrm{g} \mathrm{ml}^{-1}$, respectively.

Accuracy and Precision The accuracy and precision of the proposed procedures was ascertained based on the analysis of quality control samples. Quality control sample concentrations were $10.0,30.0$ and $60.0 \mu \mathrm{g} \mathrm{ml}^{-1}$. Five replicate quality control samples at each concentration were analyzed within $1 \mathrm{~d}$ as well as for 5 consecutive days. The standard deviations (S.D.), relative standard deviations (\%RSD), standard analytical error (SAE) and confidence limit (CL) were calculated by standard methods.

Recovery Studies Recovery experiments were carried out by standard addition method. For this, $4.0 \mathrm{ml}$ (or $6.0 \mathrm{ml}$ ) of reference irbesartan solution $\left(0.5 \mathrm{mg} \mathrm{ml}^{-1}\right)$ was transferred into a $100.0 \mathrm{ml}$ volumetric flask followed by $2.0 \mathrm{ml}$ (or $4.0 \mathrm{ml}$ ) of sample solution $\left(0.5 \mathrm{mg} \mathrm{ml}^{-1}\right)$ and volume was completed to the mark with distilled water. The nominal value was determined by the recommended procedures.

Limit of Detection (LOD) and Quantitation (LOQ) According to International Conference on Harmonisation (ICH) guidelines, ${ }^{13)}$ the following expressions are used to evaluate LOD and LOQ.

$$
\mathrm{LOD}=3.3 \times S_{0} / b \text { and } \mathrm{LOQ}=10 \times S_{0} / b
$$

where $S_{0}$ and $b$ are standard deviation and slope of the calibration line, respectively.

Evaluation of Bais The bias has been evaluated by means of point and interval hypothesis tests. ${ }^{14,15)}$ In interval hypothesis the proposed method (method 2) is accepted when the true mean is within $\pm 2 \%$ of that of the true reference method (method 1), i.e.

$$
-0.02 \mu_{1}<\left(\mu_{2}-\mu_{1}\right)<0.02 \mu_{1}
$$

The above equation can also be written as:

$$
0.98<\mu_{2} / \mu_{1}<1.02
$$

which can be generalized to

$$
\theta_{\mathrm{L}}<\mu_{2} / \mu_{1}<\theta_{\mathrm{U}}
$$

where $\theta_{\mathrm{L}}$ and $\theta_{\mathrm{U}}$ are lower and upper acceptance limits, respectively. The limits of this confidence interval can be calculated as the two roots of the following quadratic equation.

$$
\theta^{2}\left(\overline{x_{1}^{2}}-S_{\mathrm{p}}^{2} t_{\mathrm{tab}}^{2} / n_{1}\right)-2 \theta \overline{x_{1} \bar{x}_{2}}+\theta^{2}\left(\overline{x_{2}^{2}}-S_{\mathrm{p}}^{2} t_{\mathrm{tab}}^{2} / n_{2}\right)=0
$$

where

$$
\begin{aligned}
& a=\overline{x_{1}^{2}}-\frac{S_{\mathrm{p}}^{2} t_{\mathrm{tab}}^{2}}{n_{1}} \\
& b=-2 \overline{x_{1}} \overline{x_{2}} \\
& c=\overline{x_{2}^{2}}-\frac{S_{\mathrm{p}}^{2} t_{\mathrm{tab}}^{2}}{n_{2}}
\end{aligned}
$$

The values of $\theta_{\mathrm{L}}$ and $\theta_{\mathrm{U}}$ of the confidence interval can be obtained as:

$$
\begin{aligned}
& \theta_{\mathrm{L}}=\frac{-b-\sqrt{b^{2}-4 a c}}{2 a} \\
& \theta_{\mathrm{U}}=\frac{-b+\sqrt{b^{2}-4 a c}}{2 a}
\end{aligned}
$$

\section{Results and Discussion}

Spectral Studies The absorption spectrum of irbesartan in dimethyl sulfoxide-water (1:9) medium shows an absorption band at $223 \mathrm{~nm}$ (Fig. 1a). The addition of aqueous solutions of $\mathrm{KIO}_{3}$ and $\mathrm{KI}$ to the drug solution causes a change in the absorption spectrum with new characteristic bands peaking at 298 and $352 \mathrm{~nm}$ (Fig. 1c) while the mixture of $\mathrm{KIO}_{3}$ and KI solution shows two absorption maxima peaking at 275 and $290 \mathrm{~nm}$ and a negligible absorbance at $352 \mathrm{~nm}$ (Fig. 1b). The molar absorptivity is higher at $352 \mathrm{~nm}$ than those obtained at $298 \mathrm{~nm}$ and hence the absorbance measurements for the determination of irbesartan were made at $352 \mathrm{~nm}$. The equilibrium is attained in about $50 \mathrm{~min}$, which formed the basis to develop a kinetic spectrophotometric method for determination of irbesartan.

Mechanism of the Color Reaction Chando et al. ${ }^{16)}$ have suggested that the terminal methyl group of the butyl side chain of irbesartan undergoes oxidation resulting in the

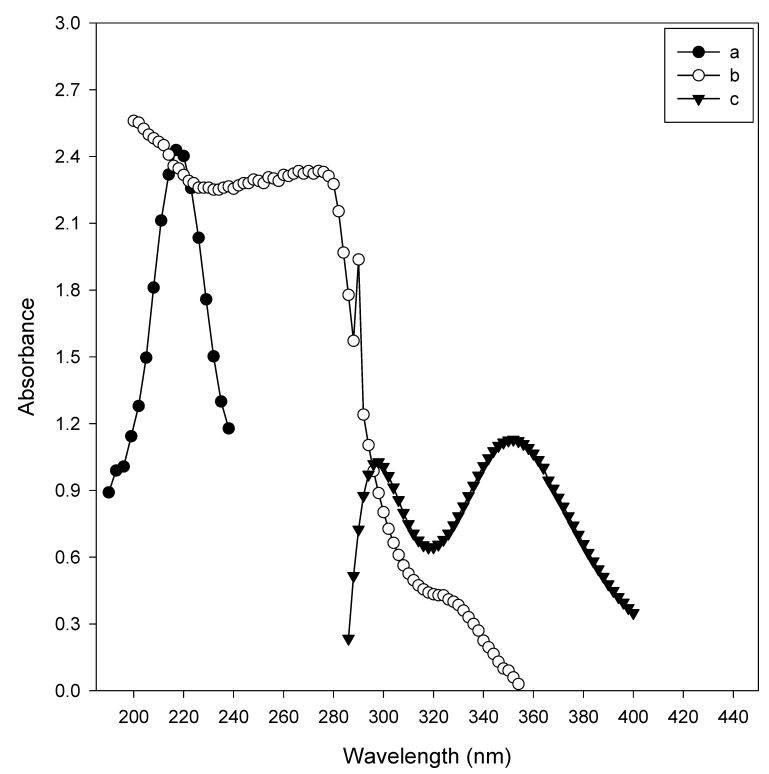

Fig. 1. Absorption Spectra of (a) $3.91 \times 10^{-6}$ M Standard Irbesartan Solution in Dimethyl Sulfoxide-Water Medium, (b) Blank Solution: $6.0 \times 10^{-4} \mathrm{M}$ Potassium Iodate and $1.15 \times 10^{-2} \mathrm{M}$ Potassium Iodide in Distilled Water, (c) Sample Solution: $60.0 \mu \mathrm{g} \mathrm{ml}^{-1}$ of Irbesartan, $6.0 \times 10^{-4} \mathrm{M}$ Potassium Iodate and $1.15 \times 10^{-2} \mathrm{M}$ Potassium Iodide in Distilled Water 
[A]

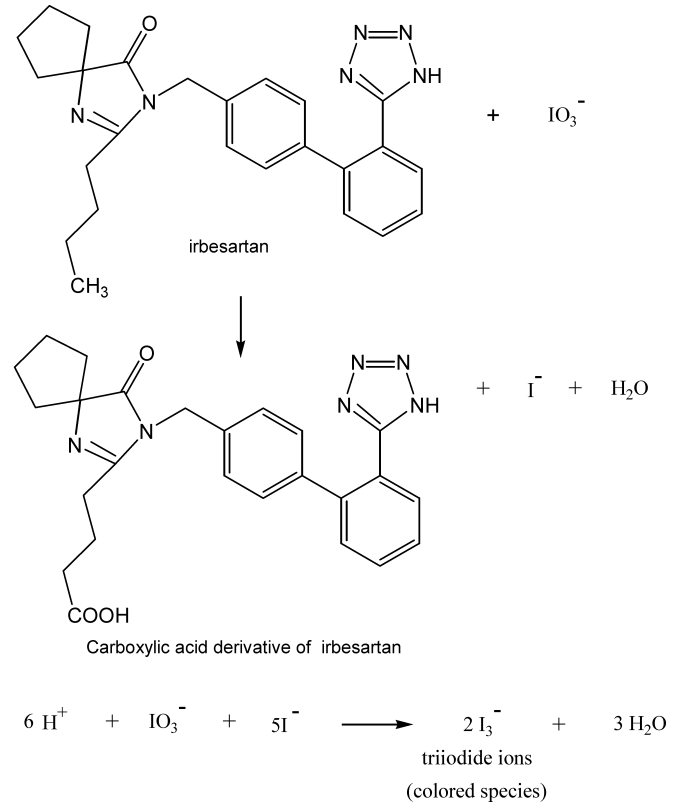

Chart 1. Reaction Sequence of the Proposed Kinetic Method

formation of a carboxylic acid derivative. In the present study, a carboxylic acid derivative is formed on oxidation of irbesartan with iodate. Then generation of triiodide ion takes place as iodide is oxidized by iodate in presence of acid form. The reaction sequence is shown in Chart 1.

Solution Stability The solution stability of irbesartan was checked by recording UV spectra of the drug for $7 \mathrm{~d}$. The reference standard of the drug showed an absorption peak at $223 \mathrm{~nm}$. The standard and quality control sample solutions were kept at room temperature for $7 \mathrm{~d}$ and it was observed that there was no change in the absorption spectra of these solutions. The solution stability was also ascertained by applying the standard and quality control samples on TLC plates coated with silica gel G (Merck Limited, Mumbai, India) and developed in ethyl acetate-toluene-acetic acid $(6: 4: 0.1 \mathrm{v} / \mathrm{v} / \mathrm{v})$ solvent system. The plates were air-dried and spots were detected in the iodine chamber. In both the cases, a single spot was observed with $R f=0.47$ corresponding to irbesartan.

Specificity The standard drug and quality control sample solutions were stressed by light and heat (up to $50^{\circ} \mathrm{C}$ ) for 2 , and 1-d time points, respectively. It was observed that stress by such conditions did not cause significant degradation. There was no change in the absorption spectra and a single spot was observed on TLC plate with $R f$ value of 0.47 . However, the samples degraded significantly when stressed by base $(0.1 \mathrm{M} \mathrm{NaOH})$ for $12 \mathrm{~h}$. All stressed samples (light and heat) and unstressed reference solution were analyzed for the active content of irbesartan, which gave acceptable recoveries of the drug. The influence of frequently encountered excipients in pharmaceutical dosage forms of irbesartan on the proposed method was studied by adding different amounts of possible interferents to the sample. It was observed that glucose, fructose, sucrose, cellulose, lactose, starch, magnesium stearate, sodium stearyl fumarate and colloidal silica did not interfere with the proposed method. However, acids such as $\mathrm{HCl}, \mathrm{H}_{2} \mathrm{SO}_{4}, \mathrm{CH}_{3} \mathrm{COOH}$ and sulphosalicylic acid and oxidizing agents such as $\mathrm{N}$-bromosuccinimide, chloramine T, am-

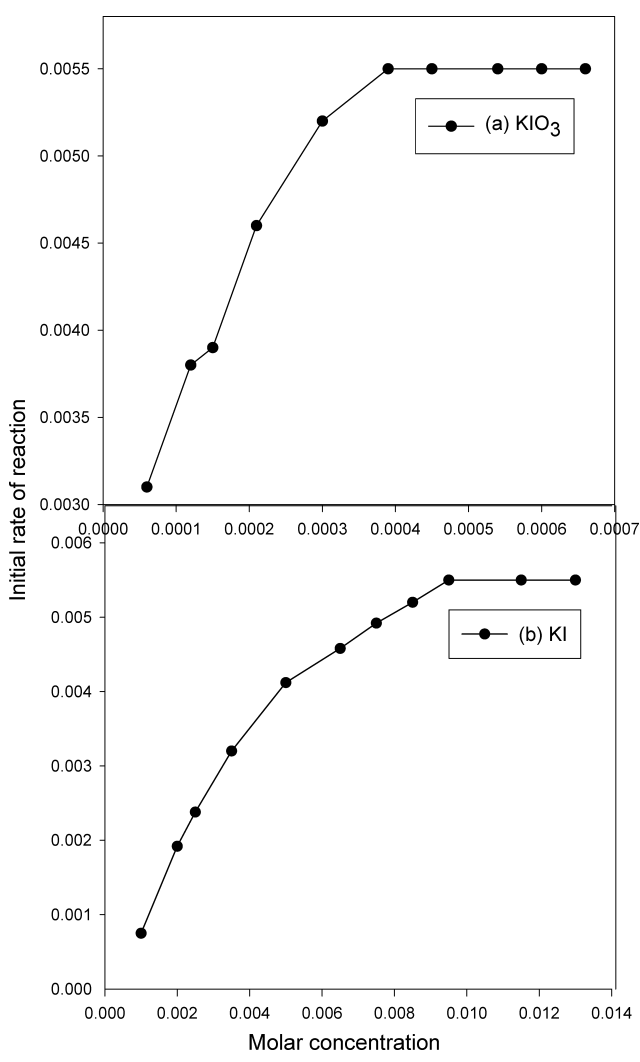

Fig. 2. Effect of the Molar Concentration of (a) $\mathrm{KIO}_{3}$ and (b) $\mathrm{KI}$ on the Initial Rate of Reaction

monium molybdate, potassium persulphate except potassium bromate interfere with the determination process.

Optimization of Variables The optimum conditions affecting the rate of reaction in the formation of triiodide ions were studied and maintained throughout the experiment to determine the quantity of irbesartan in pure form and drug formulations.

Effect of the Concentration of $\mathrm{KIO}_{3}$ The effect of the concentration of $\mathrm{KIO}_{3}$ on the initial rate of reaction was studied in the range $6.0 \times 10^{-5}-6.6 \times 10^{-4} \mathrm{M}$ (Fig. 2a) keeping all other experimental parameters constant, [irbesartran]= $1.167 \times 10^{-4}$ and $[\mathrm{KI}]=1.1 \times 10^{-2} \mathrm{M}$. It can be seen that the initial rate of reaction was increased with increasing concentration of $\mathrm{KIO}_{3}$ and became constant at $3.9 \times 10^{-4} \mathrm{M}$; above this concentration up to $6.6 \times 10^{-4} \mathrm{M}$, the initial rate of reaction was unchanged. Thus, the adoption of $5.4 \times 10^{-4} \mathrm{M} \mathrm{KIO}_{3}$ in the final solution proved to be sufficient for the maximum concentration of irbesartan used in the calibration graph.

Effect of the Concentration of KI The influence of the concentration of $\mathrm{KI}$ on the initial rate of reaction examined in the range of $1.0 \times 10^{-3}-1.3 \times 10^{-2} \mathrm{M}$. The initial rate of reaction (Fig. 2b) increased with increasing the concentration of $\mathrm{KI}$ and became constant at $9.5 \times 10^{-3} \mathrm{M}$ and beyond this concentration up to $1.30 \times 10^{-2} \mathrm{M} \mathrm{KI}$, the initial rate remained constant. Therefore $1.15 \times 10^{-2} \mathrm{M}$ KI was recommended for the determination process.

Effect of the Temperature The effect of temperature on the initial rate of reaction was investigated at 303, 308 and $313 \mathrm{~K}$. The absorbance-time curves obtained at these temperatures indicated the temperature dependence of the reaction rate. The initial rate for different concentrations of drug 
at each temperature was calculated and utilized for plotting the calibration curve. It was found that the calibration graph obtained at $303 \mathrm{~K}$ possessed good linearity $(r=0.9999)$ and is recommended that the determination be carried out at $303 \mathrm{~K}$.

Analytical Data. Initial Rate Method Under the optimized experimental conditions, high concentrations of $\mathrm{KIO}_{3}$ and KI solutions were employed, which established a pseudoorder reaction, condition with respect to the reagents concentration. Therefore, on the basis of experimental observations, kinetic equation for the reaction may be written as:

$$
\text { rate }=k[\mathrm{C}]^{n}\left[\mathrm{KIO}_{3}\right]^{m}[\mathrm{KI}]^{l}
$$

for $\left[\mathrm{KIO}_{3}\right] \geq 5.4 \times 10^{-4} \mathrm{M}$ and $[\mathrm{KI}] \geq 1.15 \times 10^{-2} \mathrm{M}$ at $303 \mathrm{~K}$.

The above equation reduces to:

$$
\text { rate }=k_{\Psi}[\mathrm{C}]^{n}
$$

where $K_{\Psi}$ is the pseudo-order rate constant, $C$ is the concentration of irbesartan and $n$ is the order of reaction. The logarithmic form of the equation may be written as:

$$
\log (\text { rate })=\log K_{\Psi}+n \log C
$$

The initial rates of reaction were determined at different concentrations of irbesartan by measuring the slopes of the initial tangent to the absorbance (at $352 \mathrm{~nm}$ )-time curves during the first $10 \mathrm{~min}$ of the reaction (Fig. 3 ) and are summarized in Table 1. The plot of $\log$ rate versus $\log C$ gave the following linear equation:

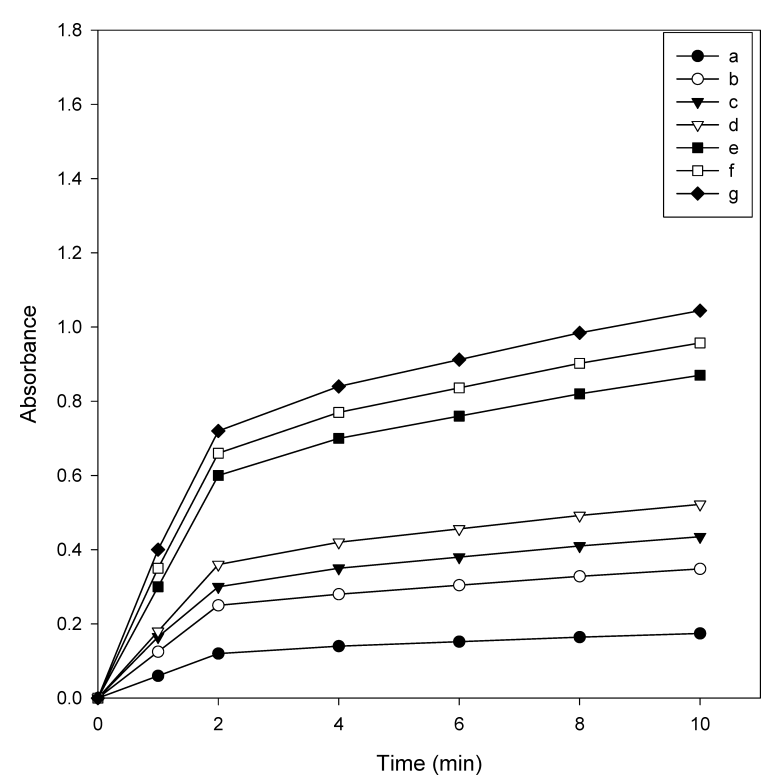

Fig. 3. Absorbance-Time Curves for the Initial Rate of Reaction at Varying Concentration of Irbesartan (a) 10, (b) 20, (c) 25, (d) 30, (e) 50, (f) 55 and $(\mathrm{g}) 60 \mu \mathrm{g} \mathrm{ml}^{-1}$ Keeping $\left[\mathrm{KIO}_{3}\right]=5.4 \times 10^{-4} \mathrm{M}$ and $[\mathrm{KI}] \geq 1.15 \times 10^{-2} \mathrm{M}$ Constant $\log ($ rate $)=1.657+1.000 \log C$

with coefficient of correlation, $r=0.9999$. The value of $n$ in the equation confirmed that the reaction is first order with respect to irbesartan and rate constant is $45.39 \mathrm{~s}^{-1}$.

A calibration curve was constructed by plotting the initial rate of reaction versus initial concentration of irbesartan, which showed a linear response showing the linear dynamic range over the concentration range of $10.0-60.0 \mu \mathrm{g} \mathrm{ml}^{-1}$. The linear regression analysis using the method of least square treatment of calibration data $(n=7)$ was made to evaluate slope, intercept and correlation coefficient. The regression of rate versus concentration of irbesartan $\left(\mu \mathrm{g} \mathrm{ml}^{-1}\right)$ gave the following linear regression equation:

Rate $=-2.138 \times 10^{-6}+1.058 \times 10^{-4} \mathrm{C}$

with a correlation coefficient $(r)$ of 0.9999 . The limits of detection (LOD) and quantitation (LOQ) were found to be 0.21 and $0.63 \mu \mathrm{g} \mathrm{ml}^{-1}$, respectively. The variance $\left(S_{0}^{2}\right)$ of the calibration line was evaluated to be $4.478 \times 10^{-11} \mu \mathrm{g} \mathrm{ml}^{-1}$ which is very low showing negligible scattering of the experimental data points around the line of regression. The values of confidence limit for the slope $\left(b \pm t S_{\mathrm{b}}\right)$ and intercept $\left(a \pm t S_{\mathrm{a}}\right)$ of the calibration line were computed ${ }^{17)}$ and found to be $1.058 \times 10^{-4} \pm 3.65 \times 10^{-7}$ and $-2.138 \times 10^{-6} \pm 1.46 \times 10^{-5}$, respectively for $n-2$ degrees of freedom at $95 \%$ confidence level. The values of the confidence limit are appreciably low thus indicating the high reproducibility of the initial rate method.

Fixed-Time Method ( $\boldsymbol{\Delta A})$ The absorbance of the yellow colored solution at $352 \mathrm{~nm}$ was recorded during the first $10 \mathrm{~min}$ at a regular interval of $2.0 \mathrm{~min}$. The change in absorbance $(\Delta \mathrm{A})$ between the times $t_{1}(2 \mathrm{~min})$ and $t_{2}(4$ or 6,8 , $10 \mathrm{~min}$ ) was computed and plotted against the concentration of irbesartan at $(n=8)$. The corresponding linear regression equations with coefficient of correlations are summarized in Table 2. It is evident from the table that the most acceptable linearity was obtained when the calibration graphs was plotted by considering the change in absorbance between 2 and

Table 1. Initial Rate of Reaction at Different Concentration of Irbesartan, Keeping $\left[\mathrm{KIO}_{3}\right]$ and $[\mathrm{KI}]$ Constant

\begin{tabular}{|c|c|c|c|c|}
\hline$\Delta \mathrm{A}$ & Calibration equation & $r$ & $\pm t S_{\mathrm{a}}$ & $\pm t S_{\mathrm{b}}$ \\
\hline $\mathrm{A}_{4}-\mathrm{A}_{2}$ & $\Delta \mathrm{A}=-1.73 \times 10^{-3}+2.06 \times 10^{-3} \mathrm{C}$ & 0.9945 & $8.100 \times 10^{-3}$ & $2.202 \times 10^{-4}$ \\
\hline $\mathrm{A}_{6}-\mathrm{A}_{2}$ & $\Delta \mathrm{A}=-3.75 \times 10^{-3}+3.25 \times 10^{-3} C$ & 0.9995 & $5.383 \times 10^{-3}$ & $1.468 \times 10^{-4}$ \\
\hline $\mathrm{A}_{8}-\mathrm{A}_{2}$ & $\Delta \mathrm{A}=-2.89 \times 10^{-3}+4.44 \times 10^{-3} \mathrm{C}$ & 0.9990 & $7.243 \times 10^{-3}$ & $1.958 \times 10^{-4}$ \\
\hline $\mathrm{A}_{10}-\mathrm{A}_{2}$ & $\Delta \mathrm{A}=-2.00 \times 10^{-3}+5.41 \times 10^{-3} C$ & 0.9989 & $9.225 \times 10^{-3}$ & $2.447 \times 10^{-4}$ \\
\hline
\end{tabular}

\begin{tabular}{cccc}
\hline \hline $\begin{array}{c}C,[\mathrm{Drug}] \\
\mathrm{moll}^{-1}\end{array}$ & $\log C$ & $\begin{array}{c}\text { Initial rate of reaction, } v \\
\mathrm{moll}^{-1} \mathrm{~s}^{-1}\end{array}$ & $\log v$ \\
\hline $2.334 \times 10^{-5}$ & -4.632 & $1.057 \times 10^{-3}$ & -2.975 \\
$4.667 \times 10^{-5}$ & -4.331 & $2.118 \times 10^{-3}$ & -2.674 \\
$5.834 \times 10^{-5}$ & -4.234 & $2.642 \times 10^{-3}$ & -2.578 \\
$7.001 \times 10^{-5}$ & -4.155 & $3.169 \times 10^{-3}$ & -2.499 \\
$1.167 \times 10^{-4}$ & -3.778 & $5.299 \times 10^{-3}$ & -2.276 \\
$1.284 \times 10^{-4}$ & -3.892 & $5.808 \times 10^{-3}$ & -2.236 \\
$1.400 \times 10^{-4}$ & -3.854 & $6.348 \times 10^{-3}$ & -2.197 \\
\hline
\end{tabular}

Table 2. Coefficient of Correlation ( $r$ ) for the Calibration Equations at $A_{4}-A_{2}, A_{6}-A_{2}, A_{8}-A_{2}$ and $A_{10}-A_{2}$ for Method $B$ 
Table 3. Evaluation of Accuracy and Precision of the Proposed Methods by Intra Day and Inter Day Assays

\begin{tabular}{|c|c|c|c|c|c|}
\hline \multirow{2}{*}{ Proposed methods } & \multicolumn{2}{|c|}{ Amount $\left(\mu \mathrm{g} \mathrm{ml}^{-1}\right)$} & \multirow{2}{*}{ RSD (\%) } & \multirow{2}{*}{$\mathrm{SAE}^{b)}$} & \multirow{2}{*}{$\mathrm{CL}^{c)}$} \\
\hline & Taken & Found \pm S.D. ${ }^{a}{ }^{a}$ & & & \\
\hline \multicolumn{6}{|l|}{ Initial rate } \\
\hline \multirow[t]{3}{*}{ Intra day assay } & 10.0 & $9.99 \pm 0.06$ & 0.64 & 0.029 & 0.080 \\
\hline & 30.0 & $29.99 \pm 0.06$ & 0.19 & 0.025 & 0.070 \\
\hline & 60.0 & $60.03 \pm 0.10$ & 0.17 & 0.045 & 0.124 \\
\hline \multirow[t]{3}{*}{ Inter day assay } & 10.0 & $10.01 \pm 0.08$ & 0.84 & 0.038 & 0.104 \\
\hline & 30.0 & $30.02 \pm 0.10$ & 0.33 & 0.045 & 0.124 \\
\hline & 60.0 & $59.97 \pm 0.14$ & 0.23 & 0.060 & 0.168 \\
\hline \multicolumn{6}{|l|}{ Fixed time $(\Delta \mathrm{A})$} \\
\hline \multirow[t]{3}{*}{ Intra day assay } & 10.0 & $9.99 \pm 0.07$ & 0.74 & 0.033 & 0.091 \\
\hline & 30.0 & $30.01 \pm 0.05$ & 0.16 & 0.022 & 0.060 \\
\hline & 60.0 & $59.97 \pm 0.06$ & 0.10 & 0.026 & 0.073 \\
\hline \multirow[t]{3}{*}{ Inter day assay } & 10.0 & $10.01 \pm 0.13$ & 1.34 & 0.060 & 0.167 \\
\hline & 30.0 & $30.04 \pm 0.09$ & 0.28 & 0.038 & 0.106 \\
\hline & 60.0 & $60.03 \pm 0.06$ & 0.11 & 0.029 & 0.079 \\
\hline
\end{tabular}

a) Mean for five independent analyses. b) SAE, standard analytical error. c) CL, confidence limit at $95 \%$ confidence level and 4 degrees of freedom $(t=2.776)$.

Table 4. Standard Addition Method for the Determination of Irbesartan in Commercial Dosage Forms

\begin{tabular}{|c|c|c|c|c|c|c|c|c|c|c|c|c|}
\hline \multirow{2}{*}{ Formulations } & \multicolumn{3}{|c|}{$\begin{array}{l}\text { Initial rate method } \\
\text { Amount }\left(\mu \mathrm{g} \mathrm{ml}^{-1}\right)\end{array}$} & \multirow{2}{*}{$\begin{array}{c}\text { Recovery } \\
(\%)\end{array}$} & \multirow{2}{*}{$\begin{array}{l}\text { RSD } \\
(\%)\end{array}$} & \multirow{2}{*}{ SAE } & \multicolumn{3}{|c|}{$\begin{array}{c}\text { Fixed time }(\Delta \mathrm{A}) \text { method } \\
\text { Amount }\left(\mu \mathrm{g} \mathrm{ml}^{-1}\right)\end{array}$} & \multirow{2}{*}{$\begin{array}{c}\text { Recovery } \\
(\%)\end{array}$} & \multirow{2}{*}{$\begin{array}{l}\text { RSD } \\
(\%)\end{array}$} & \multirow{2}{*}{ SAE } \\
\hline & Taken & Added & Found \pm S.D. ${ }^{a)}$ & & & & Taken & Added & Found \pm S.D. ${ }^{a}$ & & & \\
\hline Irbest- 150 & 20.0 & 10.0 & $29.99 \pm 0.07$ & 99.95 & 0.22 & 0.029 & 20.0 & 10.0 & $30.04 \pm 0.06$ & 100.11 & 0.23 & 0.029 \\
\hline (Biochem Pharm) & 20.0 & 30.0 & $50.04 \pm 0.05$ & 100.08 & 0.10 & 0.022 & 20.0 & 30.0 & $49.98 \pm 0.05$ & 99.96 & 0.10 & 0.022 \\
\hline Irovel-150 & 20.0 & 10.0 & $29.95 \pm 0.12$ & 99.84 & 0.39 & 0.052 & 20.0 & 10.0 & $29.98 \pm 0.12$ & 99.94 & 0.14 & 0.055 \\
\hline (Sun Pharm) & 20.0 & 30.0 & $49.97 \pm 0.06$ & 99.94 & 0.12 & 0.026 & 20.0 & 30.0 & $50.03 \pm 0.05$ & 100.05 & 0.09 & 0.021 \\
\hline Xarb-150 & 20.0 & 10.0 & $30.00 \pm 0.13$ & 100.01 & 0.44 & 0.058 & 20.0 & 10.0 & $30.00 \pm 0.08$ & 99.98 & 0.26 & 0.034 \\
\hline (NPIL) & 20.0 & 30.0 & $50.03 \pm 0.06$ & 100.05 & 0.12 & 0.026 & 20.0 & 30.0 & $50.06 \pm 0.04$ & 100.12 & 0.08 & 0.018 \\
\hline
\end{tabular}

a) Mean for five independent analyses.

6 min (i.e. $\Delta \mathrm{A}=\mathrm{A}_{6}-\mathrm{A}_{2}$ ). This fixed time was recommended for analysis. The calibration curve was linear in the range of $7.5-60.0 \mu \mathrm{g} \mathrm{ml}^{-1}$ of irbesartan. The values of LOD, LOQ and variance were found to be $2.40,7.26$ and $5.57 \times$ $10^{-6} \mu \mathrm{g} \mathrm{ml}^{-1}$, respectively.

Activation Parameters of the Proposed Methods The apparent activation parameters were evaluated by studying the reaction rate at 303,308 and $313 \mathrm{~K}$ keeping the following reaction conditions:

$[$ irbesartan $]=4.667 \times 10^{-5} \mathrm{M},\left[\mathrm{KIO}_{3}\right]=6.0 \times 10^{-4} \mathrm{M},[\mathrm{KI}]=1.15 \times 10^{-2} \mathrm{M}$

The Arrhenius curve was obtained by plotting $\ln k_{\text {obs. }} v e r-$ sus $1 / T$ and found to be linear with coefficient of correlation, $r=-0.9995$. The activation energy $\left(E_{\mathrm{a}}\right)$ was calculated from the slope $\left(-E_{\mathrm{a}} / R\right)$ of the Arrhenius curve and found to be $70.95 \pm 0.43 \mathrm{~kJ} \mathrm{~mol}^{-1}$. The values of enthalpy $\left(\Delta H^{\ddagger}\right)$, entropy $\left(\Delta S^{\ddagger}\right)$ and free energy of activation $\left(\Delta G^{\ddagger}\right)$ of the reaction were also calculated using Eyring equation:

$$
\ln \frac{k}{T}=\left[\ln \left(k_{\mathrm{b}} / h\right)+\frac{\Delta S^{\ddagger}}{R}\right]-\frac{\Delta H^{\ddagger}}{R} \frac{1}{T}
$$

The Eyring plot of $\ln k_{\text {obs. }} / T$ versus $1 / T$ was linear with coefficient of correlation, $r=-0.9995 . \Delta H^{*}$ and $\Delta S^{\star}$ were calculated from the slope $\left(-\Delta H^{*} / R\right)$ and the intercept $\left[\ln \left(k_{\mathrm{b}} / h\right)+\right.$ $\left.\Delta S^{\ddagger} / R\right]$ of the Eyring graph and were found to be $68.48 \pm 0.21 \mathrm{~kJ} \mathrm{~mol}^{-1}$ and $16.54 \pm 0.24 \mathrm{~J} \mathrm{~K}^{-1} \mathrm{~mol}^{-1}$, respectively. The Gibbs free energy of activation i.e. $\Delta G^{\star}$ at $303 \mathrm{~K}$ was evaluated by the equation $\left(\Delta G^{\ddagger}=\Delta H^{*}-T \Delta S^{\ddagger}\right)$ and found to be $-4.94 \pm 0.07 \mathrm{~kJ} \mathrm{~mol}^{-1}$. The values of activation parameters indicated that the reaction is feasible.

Accuracy and Precision of the Proposed Methods The accuracy and precision of the proposed methods was established by performing intra day and inter day assays by determining the content of irbesartan in quality control samples at three different concentration levels (low, medium and high). These assays were investigated by measuring five independent analyses at $10.0,30.0$ and $60.0 \mu \mathrm{g} \mathrm{ml}^{-1}$ concentration levels within $1 \mathrm{~d}$ and on 5 consecutive days, respectively (Table 3). The standard deviation, relative standard deviation and standard analytical error obtained by both methods are acceptable i.e. within the permissible bias range and therefore can be considered to be satisfactory.

Validity of the Proposed Methods Standard addition method was employed to check the validity of the proposed procedures. In this method, a known amount of pure irbesartan was added to its formulated tablets at two different concentration levels and the nominal value of the drug was calculated following the proposed procedures. The results are summarized in Table 4. As can be seen from the table, that the recoveries obtained by both the procedures are quite satisfactory with low RSD.

Robustness The robustness of the proposed procedure was ascertained by challenging the following operational parameters:

- volume of $0.003 \mathrm{M} \mathrm{KIO}_{3}( \pm 0.4 \mathrm{ml})$

- volume of $0.05 \mathrm{M} \mathrm{KI}( \pm 0.3 \mathrm{ml})$ 
Table 5. Point and Interval Hypothesis Tests: Evaluation of the Applicability of the Proposed Methods with the Reference Method at $95 \%$ Confidence Level

\begin{tabular}{|c|c|c|c|c|c|c|c|c|c|c|c|c|c|c|}
\hline \multirow{3}{*}{ Formulations } & \multicolumn{6}{|c|}{ Point hypothesis tests } & \multicolumn{8}{|c|}{ Interval hypothesis tests } \\
\hline & \multicolumn{2}{|c|}{ Initial rate method } & \multicolumn{2}{|c|}{$\begin{array}{l}\text { Fixed time } \\
(\Delta \mathrm{A}) \text { method }\end{array}$} & \multicolumn{2}{|c|}{ Reference method } & \multicolumn{4}{|c|}{ Initial rate method } & \multicolumn{4}{|c|}{ Fixed time $(\Delta \mathrm{A})$ method } \\
\hline & $\begin{array}{c}\text { Recovery } \\
(\%)\end{array}$ & $\begin{array}{c}\mathrm{RSD}^{a)} \\
(\%)\end{array}$ & $\begin{array}{c}\text { Recovery } \\
(\%)\end{array}$ & $\begin{array}{l}\mathrm{RSD}^{a)} \\
(\%)\end{array}$ & $\begin{array}{c}\text { Recovery } \\
(\%)\end{array}$ & $\begin{array}{l}\text { RSD } \\
(\%)\end{array}$ & $\begin{array}{c}t- \\
\text { values }\end{array}$ & $\begin{array}{c}F \text { - } \\
\text { values }\end{array}$ & $\theta_{\mathrm{L}}$ & $\theta_{\mathrm{U}}$ & $\begin{array}{c}t- \\
\text { values }\end{array}$ & $\begin{array}{c}F \text { - } \\
\text { values }\end{array}$ & $\theta_{\mathrm{L}}$ & $\theta_{\mathrm{U}}$ \\
\hline $\begin{array}{l}\text { Irbest } 150 \\
\text { (Biochem) }\end{array}$ & 100.12 & 0.46 & 100.15 & 0.41 & 100.24 & 1.01 & 0.62 & 2.84 & 0.99 & 1.01 & 0.22 & 3.35 & 0.99 & 1.01 \\
\hline $\begin{array}{l}\text { Irovel } 150 \\
\text { (Sun) }\end{array}$ & 99.86 & 0.87 & 100.09 & 0.80 & 100.06 & 0.65 & 0.39 & 1.78 & 0.98 & 1.01 & 0.06 & 1.13 & 0.98 & 1.01 \\
\hline $\begin{array}{l}\text { Xarb } \\
\text { (NPIL) }\end{array}$ & 99.93 & 0.84 & 100.09 & 0.80 & 99.87 & 0.77 & 0.15 & 1.47 & 0.98 & 1.01 & 0.25 & 1.60 & 0.98 & 1.01 \\
\hline
\end{tabular}

Table 6. Comparison of the Proposed Kinetic Spectrophotometric Method with Other Methods for Determination of Irbesartan

\begin{tabular}{|c|c|c|c|}
\hline Methods & $\begin{array}{l}\text { Linear dynamic } \\
\text { range }\left(\mu \mathrm{g} \mathrm{ml}^{-1}\right)\end{array}$ & $\begin{array}{l}\text { RSD } \\
(\%)\end{array}$ & References \\
\hline HPTLC & $60-180$ & $1.81-2.49$ & 3) \\
\hline HPLC & $0.001-1.0$ & $<8$ & 5) \\
\hline CZE & $60-300$ & 0.93 & 7) \\
\hline CZE & $80-400$ & $0.28-0.49$ & 8) \\
\hline \multicolumn{4}{|l|}{ Spectrophotometry } \\
\hline Initial rate method & $10-60$ & $0.17-0.84$ & This work \\
\hline Fixed-time method $(\Delta \mathrm{A})$ & $7.5-60$ & $0.10-0.74$ & This work \\
\hline
\end{tabular}

Under these conditions quality control samples were analyzed at two concentration levels: 25.0 and $45.0 \mathrm{mg} \mathrm{ml}^{-1}$. The results are quite satisfactory with acceptable recovery and low RSD values.

Applicability of the Proposed Methods The applicability of the proposed methods for the assay of irbesartan in drug formulations has been tested on commercially available tablets. The results of the proposed methods were statistically compared with those of the developed reference method using point and interval hypothesis tests. Table 5 shows that the calculated $t$ - (paired) and $F$-values at $95 \%$ confidence level are less than the theoretical ones, confirming no significant difference between the methods compared. It can also be seen from the table that the bias evaluated by interval hypothesis test is within the acceptable range of $\phi_{\mathrm{L}}=0.98$ and $\phi_{\mathrm{U}}=1.02$.

The performance of the proposed kinetic spectrophotometric method was compared with other methods (Table 6). It can be seen from Table 6 that HPTLC method is time consuming and tedious. The precision is also somewhat poor. HPLC method is sensitive enough but it requires solid phase extraction of irbesartan before analysis and RSD is also higher. $\mathrm{CZE}^{7,8)}$ gives accurate results but the technique is expensive. The present kinetic spectrophotometric method is simple, fast and accurate because it does not involve any pretreatment step prior to analysis.

\section{Conclusion}

The proposed method is a direct method, applicable in aqueous medium at $30^{\circ} \mathrm{C}$ and thus there is no fear of decom- position of the drug due to heat, acid or base. No interferences have been observed with excipients found in drug formulations. The proposed method is a stability-indicating assay method for the determination of irbesartan in the presence of its degradation products. Therefore, it is concluded that the proposed method is suitable for the determination of irbesartan in drug formulations and can be used for routine quality control analyses of active drug in the laboratories of hospitals, pharmaceutical industries and research institutions.

Acknowledgements Financial assistance provided by Council of Scientific and Industrial Research (CSIR), New Delhi, India to Dr. Syed Najmul Hejaz Azmi as Research Associate (Award No. 9/112(329)/2002-EMR-I) is gratefully acknowledged. The authors wish to express their gratitude to $\mathrm{M} / \mathrm{s}$. Biochem Pharmaceutical Industries (Mumbai, India) for the sample of reference standard of irbesartan.

\section{References}

1) Markham A., Spencer C. M., Jarvis B., Drugs, 59, 1187-1206 (2000).

2) "Martindale the Extra Pharmacopoeia," 33rd ed., Royal Pharmaceutical Society, London, 2002, p. 914.

3) Sane R. T., Francis M., Pawar S., Indian Drugs, 39, 32-35 (2002).

4) Erk N., J. Chromatogr. B, 784, 195-201 (2003).

5) Chang S. Y., Whigan D. B., Vachharajani N. N., Patel R., J. Chromatogr. B, 702, 149-155 (1997).

6) Li J., Wu Q., Wang L., Yaowu Fenxi Zazhi, 21, 249-250 (2001).

7) Hillaert S., Vanden-Bossche W., J. Chromatogr. A, 979, 323-333 (2002).

8) Hillaert S., Vanden-Bossche W., J. Pharm. Biomed. Anal., 31, 329339 (2003).

9) Isabel I., Rodenas V., Garcia S., Sanchez-Pedreno C., J. Pharm. Biomed. Anal., 29, 299-305 (2002).

10) Erk N., Pharmazie, 58, 543-548 (2003).

11) Perez-Bendito D., Gomez-Hens A., Silva M., J. Pharm. Biomed. Anal., 14, 917-930 (1996)

12) Sierra-Jimenez F., Sanchez-Pedreno C., Anales real Soc. Espan. Fis. y quim., $54 \mathrm{~B}, 541-552$ (1958).

13) International conference on Harmonisation, ICH Harmonised Tripartite Guideline-Text on Validation of Analytical Procedures, Fed. Regist., 60, 11260 (1995).

14) Hartmann C., Smeyers-Verbeke J., Penninckx W., Heyden Y. V., Vankeerberghen P., Massart D. L., Anal. Chem., 67, 4491 - 4499 (1995).

15) Canada Health Protection Branch, Drugs Directorate guidelines, Acceptable methods, Ministry of National Health and Welfare, Draft, 1992.

16) Chando T. J., Everett D. W., Kahle A. D., Starrett A. M., Vachharajani N., Shyu W. C., Kriplani K. J., Barbhaiya R. H., Drug Metab. Dispos., 26, 408-417 (1998).

17) Miller J. N., Analyst, 116, 3-14 (1991). 